\title{
Cell-based gene therapy modifies matrix remodeling after a myocardial infarction in tissue inhibitor of matrix metalloproteinase-3-deficient mice
}

Denis Angoulvant, MD, PhD, Shafie Fazel, MD, PhD, Richard D. Weisel, MD, Teresa Y. Y. Lai, MSc, Paul W. Fedak, MD, PhD, Liwen Chen, MSc, Shahin Rafati, MD, MSc, Charit K. Seneviratne, PhD, Norbert Degousee, PhD, and Ren-Ke Li, MD, PhD

Objective: Cell-based gene therapy can enhance the effects of cell transplantation by temporally and spatially regulating the release of the gene product. The purpose of this study was to evaluate transient matrix metalloproteinase inhibition by implanting cells genetically modified to overexpress a natural tissue inhibitor of matrix metalloproteinases (tissue inhibitor of matrix metalloproteinase-3) into the hearts of mutant (tissue inhibitor of matrix metalloproteinase-3-deficient) mice that exhibit an exaggerated response to myocardial infarction. Following a myocardial infarction, tissue inhibitor of matrix metalloproteinase-3-deficient mice undergo accelerated cardiac dilatation and matrix disruption due to uninhibited matrix metalloproteinase activity. This preliminary proof of concept study assessed the potential for cell-based gene therapy to reduce matrix remodeling in the remote myocardium and facilitate functional recovery.

Methods: Anesthetized tissue inhibitor of matrix metalloproteinase-3-deficient mice were subjected to coronary ligation followed by intramyocardial injection of vector-transfected bone marrow stromal cells, bone marrow stromal cells overexpressing tissue inhibitor of matrix metalloproteinase-3, or medium. Functional, morphologic, histologic, and biochemical studies were performed $0,3,7$, and 28 days later.

Results: Bone marrow stromal cells and bone marrow stromal cells overexpressing tissue inhibitor of matrix metalloproteinase-3 significantly decreased scar expansion and ventricular dilatation 28 days after coronary ligation and increased regional capillary density to day 7. Only bone marrow stromal cells overexpressing tissue inhibitor of matrix metalloproteinase-3 reduced early matrix metalloproteinase activities and tumor necrosis factor $\alpha$ levels relative to medium injection. Bone marrow stromal cells overexpressing tissue inhibitor of matrix metalloproteinase-3 were also more effective than bone marrow stromal cells in preventing progressive cardiac dysfunction, preserving remote myocardial collagen content and structure, and reducing border zone apoptosis for at least 28 days after implantation.

Conclusions: Tissue inhibitor of matrix metalloproteinase-3 overexpression enhanced the effects of bone marrow stromal cells transplanted early after a myocardial infarction in tissue inhibitor of matrix metalloproteinase-3deficient mice by contributing regulated matrix metalloproteinase inhibition to preserve matrix collagen and improve functional recovery.

Supplemental material is available online.

We recently demonstrated that the paracrine benefits of cell transplantation ${ }^{1}$ can be enhanced by transfecting the implanted cells with genes to increase their cytokine production ${ }^{2-4}$; these

\footnotetext{
From the Division of Cardiovascular Surgery, Toronto General Research Institute, Toronto General Hospital, University of Toronto, Toronto, Ontario, Canada.

This study was funded primarily by a grant from the Heart and Stroke Foundation of Ontario (T6069) to R.-K.L. and in part by a grant from the Canadian Institutes for Health Research (MOP14795) to R.-K.L. and a fellowship from the Fédération Française de Cardiologie to D.A.

Received for publication June 17, 2008; revisions received July 25, 2008; accepted for publication Aug 16, 2008.

Address for reprints: Ren-Ke Li, MD, PhD, MaRS Centre, Toronto Medical Discovery Tower, Room 3-702, 101 College St, Toronto, Ontario, Canada, M5G 1L7 (E-mail: renkeli@uhnres.utoronto.ca).

J Thorac Cardiovasc Surg 2009;137:471-80

$0022-5223 / \$ 36.00$

Copyright (c) 2009 by The American Association for Thoracic Surgery

doi:10.1016/j.jtcvs.2008.08.031
}

"cell-based gene therapies" permit the temporally and spatially regulated release of the gene product. This study assessed the potential for this technique to reduce postmyocardial infarction (MI) matrix remodeling in the remote myocardium and facilitate functional recovery. Cell-based gene therapy could represent a clinically relevant method to prevent congestive heart failure.

After an MI, diminished elasticity and increased wall stress cause the infarcted region to thin and expand while the remote myocardium undergoes extensive remodeling. An increase in the activity of matrix metalloproteinases (MMPs) relative to that of their natural tissue inhibitors (TIMPs) contributes to ventricular dilatation and dysfunction $^{5}$ through remodeling of the extracellular matrix (ECM), a dynamic structure that provides a scaffold for cardiomyocytes, facilitates contraction, and supports homeostasis. ${ }^{6}$ Although the importance of modifying post-MI matrix remodeling using MMP inhibitors has been established, ${ }^{7}$ clinically relevant strategies have been difficult to 


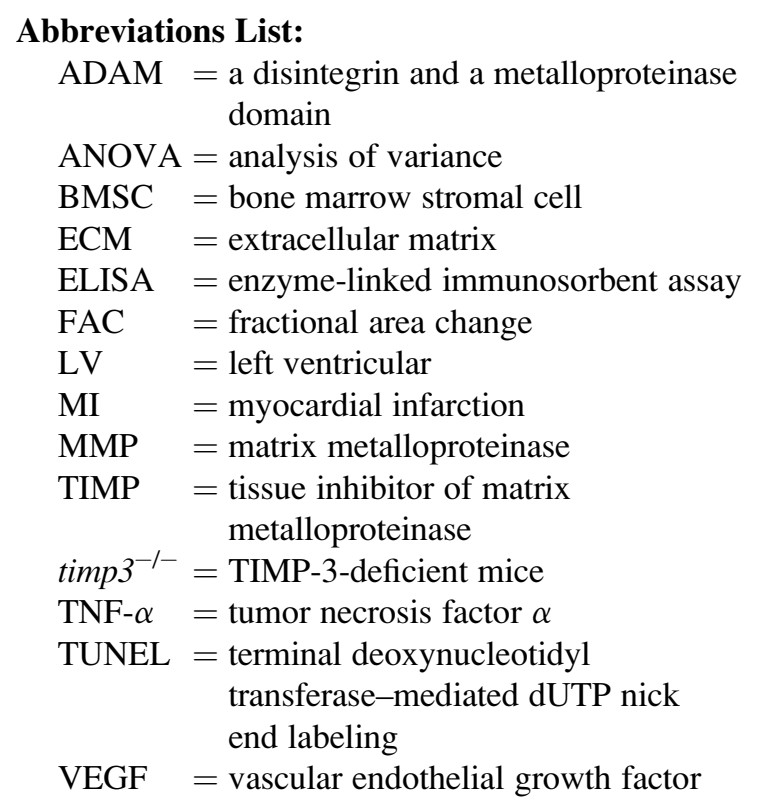

implement $^{8}$ : Chronic administration of MMP inhibitors ${ }^{9,10}$ and the initial clinical trials ${ }^{11}$ were not beneficial, and gene therapies ${ }^{12}$ are nonspecific. ${ }^{10}$ Implanting cells genetically modified to overexpress TIMP-3 into the heart after an MI may regulate MMP inhibition in the infarcted and remote regions, ${ }^{10}$ establishing the proof of concept for cell-based gene therapy as an effective, clinically relevant approach to matrix modulation.

We evaluated cell-based gene therapy in TIMP-3 deficient $\left(\right.$ timp $\left.-3^{-1}\right)$ mice, a model in which we previously reported spontaneous heart failure after age 12 months due to unopposed ECM degradation ${ }^{13,14}$ and premature heart failure in response to coronary ligation. ${ }^{15}$

\section{MATERIALS AND METHODS \\ Animals}

All experimental procedures performed on animals were approved by the Animal Care Committee of the University Health Network, according to the "Guide for the Care and Use of Laboratory Animals" (National Academy Press, 1996). Eight- to 10-week-old C57BL/6 mice were obtained from Jackson Laboratories (Bar Harbor, Maine). Timp $-3^{-}$C57BL/6 mice were generated as previously described. ${ }^{13}$

\section{In Vitro Studies}

Bone marrow stromal cells: Isolation, transfection, and characterization. Procedures to generate the bone marrow stromal cells (BMSCs) employed in these studies are described in detail in Appendix E1 (supplementary methods). Briefly, adherent cells harvested from C57BL/6 mice were transfected by liposomal lipofectamine 2000 (Invitrogen) with a purified plasmid consisting of cDNA for murine TIMP-3 cloned into pcDNA3. $1^{+}$(Invitrogen), as previously described. ${ }^{16}$ Cellular TIMP-3 mRNA levels were assessed by semiquantitative reverse-transcriptase polymerase chain reaction, using specific primers, as previously described. ${ }^{17}$
Protein levels of synthesized (BMSC lysate) and secreted (supernatant) TIMP-3 were evaluated with an immunoblotting procedure. MMP-2 protein levels in the cultured cells and culture medium were quantified by Western blot. MMP-2 activities were evaluated using gelatin zymography, as previously described. ${ }^{14}$

\section{In Vivo Studies}

Surgical procedure. In the timp $-3^{--}$mouse model, the left coronary artery was permanently ligated proximally under the left atrial appendage through a thoracotomy. Ischemia was confirmed by the appearance of hypokinesis and pallor distal to the occlusion, and by ST elevation (electrocardiographic monitoring). The animals were randomly separated into 3 groups. At 5 minutes after ligation, BMSCs transfected 3 days earlier with TIMP3 plasmid (BMSC-T3 group) or vector (BMSC group) were delivered by 3 direct, intramyocardial injections $\left(1 \times 10^{5}\right.$ cells in $5 \mu \mathrm{L}$ of Iscove's modified Dulbecco's medium per injection) into 3 separate points within the infarcted area (identified visually as a dark brown area). Control animals (medium control group) received 3 injections of culture medium $(5 \mu \mathrm{L}$ per injection). Early mortality for the surgical procedure was $26 \%$. Assessments were performed before coronary ligation and cell or medium implantation ( 0 days), early after coronary ligation and implantation ( 3 and 7 days), and late after ligation/implantation (28 days). Measurements were taken in a blinded fashion so that operators performing echocardiographic, histologic, and biochemical analyses were not aware of the groups to which the animals were randomized.

Functional assessment. Left ventricular (LV) dilatation and systolic function were evaluated by echocardiography (Sequoia C256 System, Siemens Medical, Malvern, Penn.); 15-MHz linear array transducer) prior to and 3, 7, and 28 days after MI and cell or medium implantation ( $\mathrm{n}=6$ per group). Detailed procedures are described in Appendix E1 (supplementary methods). Fractional area change (FAC) was calculated from 2-dimensional images.

Morphometric assessment. At 28 days after implantation $(\mathrm{n}=6$ each for medium, BMSC, BMSC-T3 groups; $\mathrm{n}=3$ for normal myocardium), hearts were fixed and sliced transversely (1-mm-thick slices), then photographed for the measurement of infarct area (as a percentage of LV area) and body weight-indexed LV chamber volume. Detailed procedures are described in Appendix E1 (supplementary methods).

Remote myocardial collagen content and structure. Twenty-eight days after implantation, LV slices from the perfusion-fixed hearts ( $\mathrm{n}=6$ each for medium, BMSC, BMSC-T3 groups; $\mathrm{n}=4$ for normal myocardium) were paraffin embedded, cut into $15-\mu \mathrm{m}$-thick sections, and stained with $0.1 \%$ picrosirius red as previously described. ${ }^{18}$ Sections were imaged using a laser scanning confocal microscope (MRC 1024, Bio-Rad, Hercules, Calif). Five fields ( $n=5$ per heart) were randomly selected from the remote myocardium (viable tissue located in the lateral wall of the LV), as previously described. ${ }^{6}$ For each image, total collagen content $\left(\%\right.$ pixel $\left.^{2}\right)$ and average perimysial collagen fibril length and diameter (in micrometers after image scaling) were measured.

Apoptosis. Frozen sections from hearts harvested on days 3, 7, and 28 following implantation ( $\mathrm{n}=5$ per group per time point) were subjected to terminal deoxynucleotidyl transferase-mediated dUTP nick end labeling (TUNEL) staining (in situ cell death detection kit AP, Roche, Basel, Switzerland), as previously described. ${ }^{19}$ For each sample, apoptotic nuclei counts from 5 random microscope fields from the infarct border zone (identified using hematoxylin and eosin staining for basic histologic structures on the preceding serial section) were averaged, and apoptosis was expressed as the mean percentage of apoptotic nuclei/total nuclei per field.

Capillary density. Frozen sections from hearts harvested on days 3 and 7 following implantation ( $n=5$ per group per time point) were immunohistochemically stained with immunoglobulin G rat-anti-mouse CD31 antibody. For each sample, capillary density per millimeter squared was calculated from the mean number of capillaries (large, CD31 $1^{+}$structures) counted in 5 random, high-powered microscope fields $\left(0.05 \mathrm{~mm}^{2}\right)$ from 

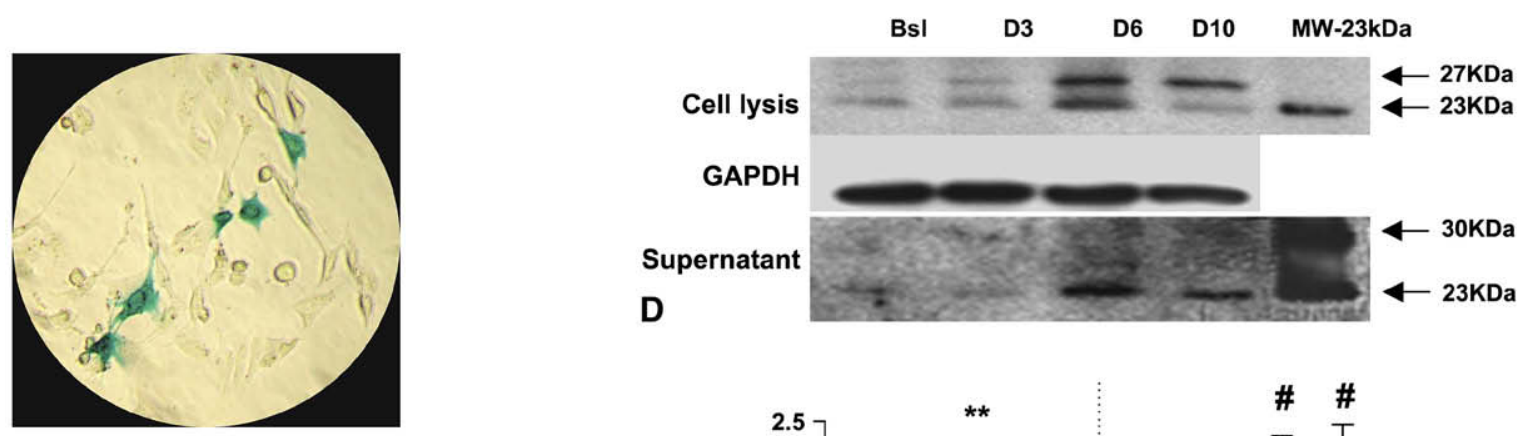

A

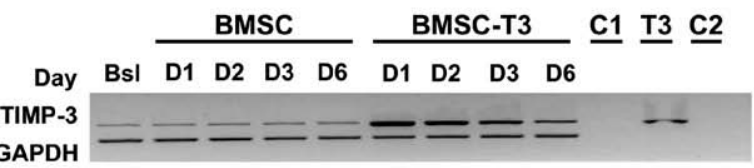

B

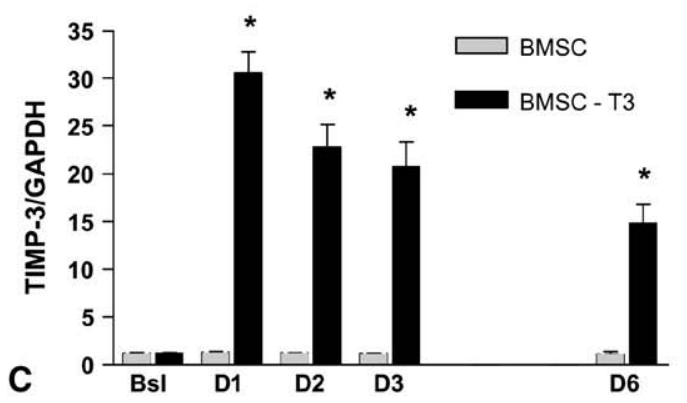

E

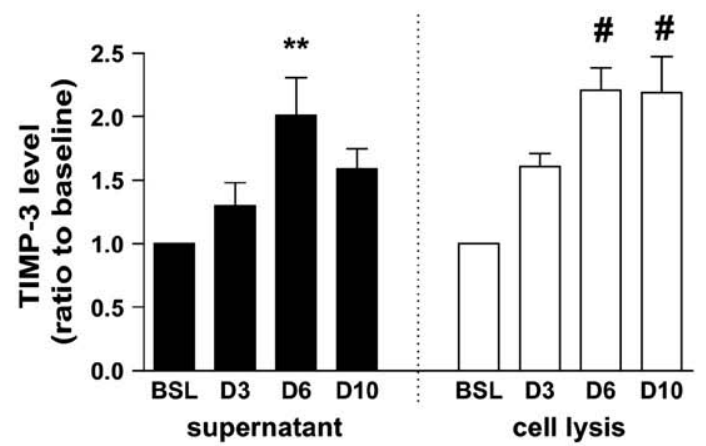

$\mathbf{F}$

G
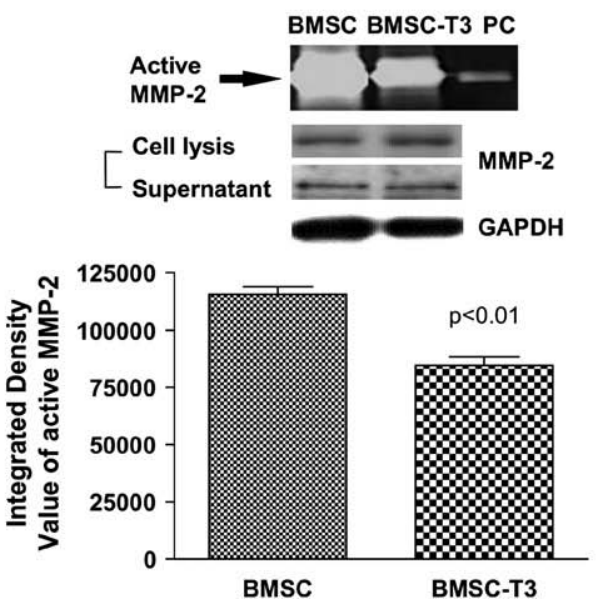

FIGURE 1. In vitro analysis of tissue inhibitor of matrix metalloproteinase-3 (TIMP-3) and matrix metalloproteinase-2 (MMP-2). A, Transfection efficiency. $\beta$-Galactosidase control vector expression (in blue) 3 days after transfection into bone marrow stromal cells $(B M S C s ; \times 400)$. B, C, Semiquantitative reversetranscriptase polymerase chain reaction (B) and densitometry (TIMP-3 mRNA levels normalized relative to glyceraldehyde-3-phosphate dehydrogenase [GAPDH] expression: TIMP-3/GAPDH). (C), Analyses showing TIMP-3 mRNA levels and GAPDH expression at days (D) 1, 2, 3, and 6 after cultured BMSCs were transfected with timp-3 (BMSC-T3) or vector (BMSC). $B s l$, baseline; $C 1$, control sample without reverse transcription; $T 3$, TIMP-3 plasmid; $C 2$, solution control; $\mathrm{n}=5$ gels in $(\mathrm{C}) .{ }^{*} P<.05$ compared with Bsl. D, E, Time course analysis of TIMP-3 protein levels by immunoblot in cell lysis and supernatant at Bsl and days (D) 3, 6, and 10 after timp-3 transfection. Bsl, Nontransfected cells (cell lysis) or culture medium (supernatant); $M W$, molecular weight; $\mathrm{n}=6$ gels in $\mathrm{E}$. $* * P<.01$ compared with Bsl; \#P<.001 compared with Bsl. F-H, Gelatin zymography (F) with immunoblot (G) and densitometry analysis $(\mathrm{H})$, showing a significant reduction $(\sim 30 \% ; P<.01)$ in MMP-2 activity in the supernatant, with no difference in MMP-2 expression in the cell lysis or supernatant or in internal standard GAPDH expression, 3 days after transfection in the BMSC-T3 group relative to the BMSC group. PC, Positive control; $\mathrm{n}=6$ samples per group in $\mathrm{H}$, equal amounts of protein loaded. Data are mean \pm standard error of the mean.

the infarct border zone (identified using hematoxylin and eosin staining on the preceding serial section).

Myocardial MMP expression and activity. Myocardial samples from animals sacrificed on days 3, 7, and 28 after implantation $(n=6$ mice per group per time point) were snap-frozen. Half of each heart homogenate was treated at $4^{\circ} \mathrm{C}$ for 1 hour with an extraction buffer for determination of MMP- 2 and -9 activities. The other half was treated at $4^{\circ} \mathrm{C}$ for 1 hour with an extraction buffer containing $0.15 \mathrm{NaCl}, 5 \mathrm{mmol} / \mathrm{L}$ ethylenediamine- tetraacetic acid, $1 \%$ Triton $\mathrm{X}-100,10 \mathrm{mmol} / \mathrm{L}$ Tris-Cl, and small amounts of proteinase inhibitor cocktail for measurement of MMP-2 and -9 protein levels. Protein levels and activities were evaluated as described in Appendix E1 (supplementary methods), with integrated density values of active MMP-9 and -2 used as markers of MMP-9 and -2 activation.

Myocardial tumor necrosis factor $\alpha$ levels. Mice were sacrificed on days 3 and 7 after implantation ( $n=6$ per group). Hearts from normal mice $(n=4)$ were collected as normal controls. The myocardial tissue 
MMP-9

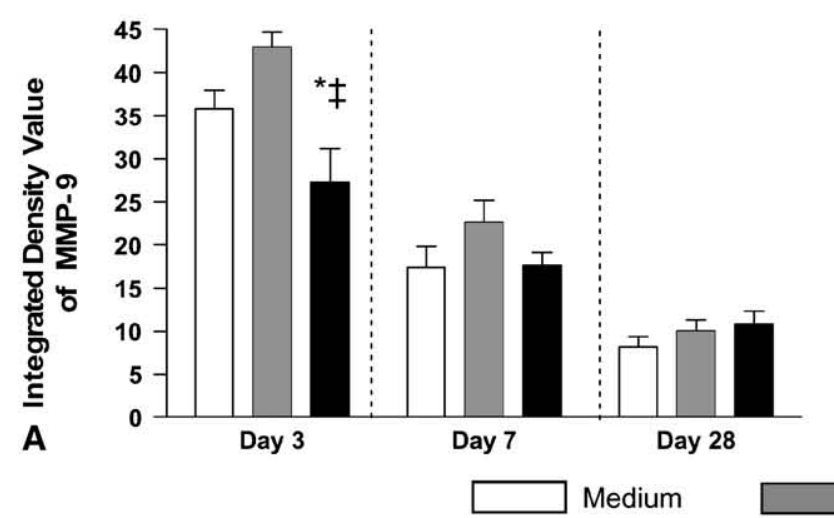

Medium



BMSC

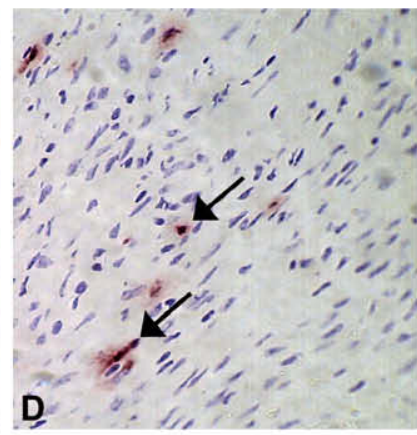

MMP-2

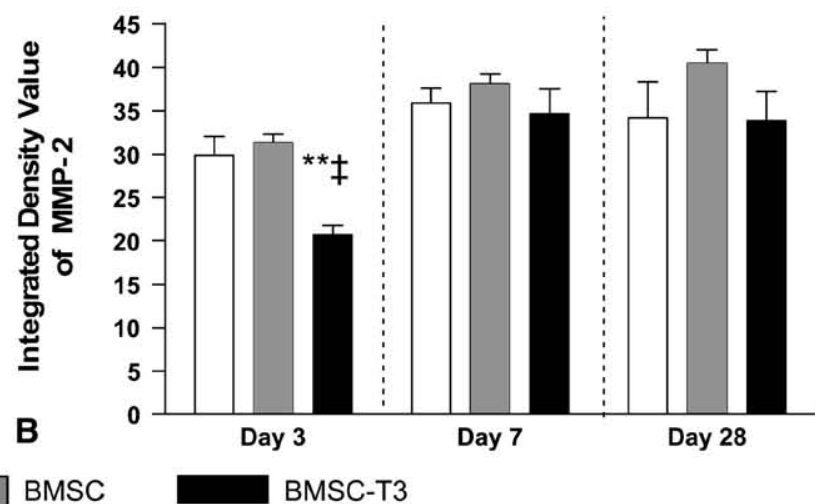

No MI

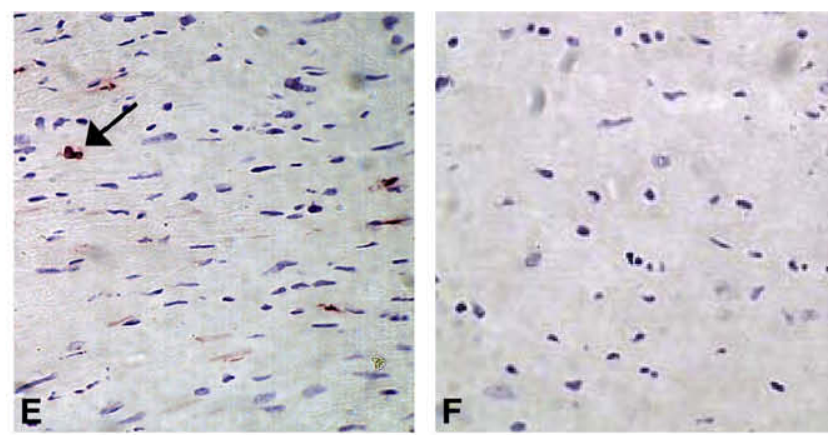

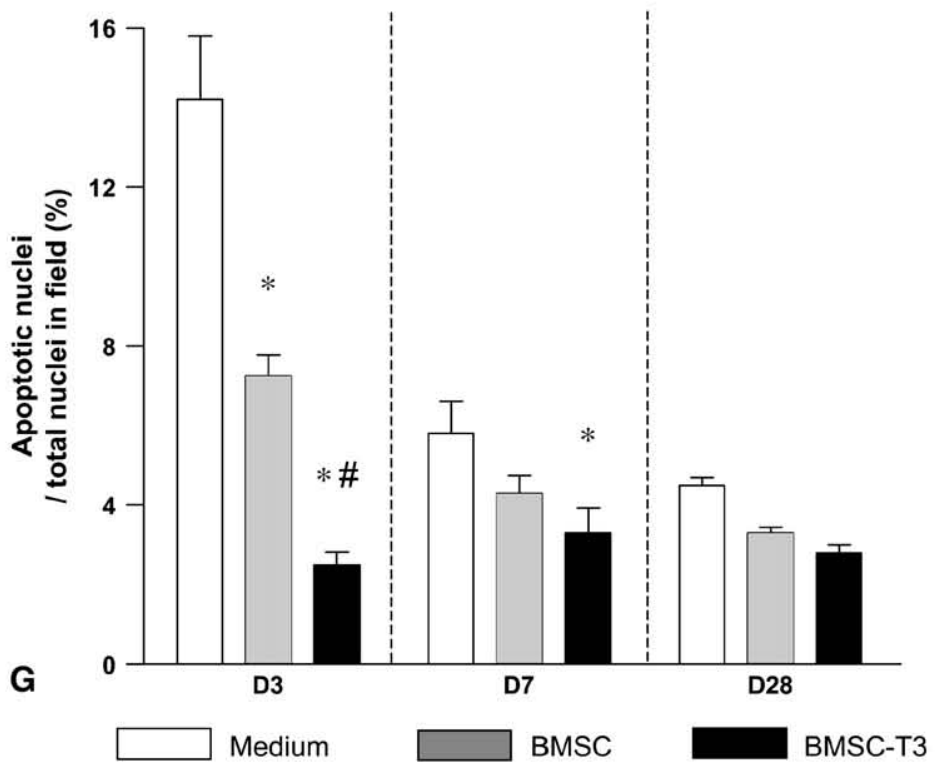


was homogenized and supernatants were collected. Tumor necrosis factor $\alpha$ (TNF- $\alpha$ ) levels were quantified using enzyme-linked immunosorbent assay (ELISA) with commercial Murine TNF- $\alpha$ ELISA Kit (Endogen, Rockford, Ill.) as per manufacturer's instructions. Each sample at each time point was performed in triplicate, then averaged.

\section{Statistical Analyses}

Results are expressed as mean \pm standard error of the mean unless otherwise specified. Data recorded at several time points were analyzed using 2-way, repeated measures analysis of variance (ANOVA; to detect time and group effects) followed (when significant) by Bonferoni's post hoc multiple comparison test, or using 1-way ANOVA followed by Tukey multiple comparison test. Unless otherwise specified, data recorded at a single time point were analyzed using 1-way ANOVA followed by Newman-Keuls multiple comparison test. Differences were considered statistically significant at $P<.05$.

\section{RESULTS}

\section{In Vitro Studies}

Appendix E1 (supplementary results) describes the phenotype of cultured BMSCs at passage 20 that were employed for the in vivo studies. The efficiency of gene transfection was $15 \% \pm 2 \%$. As shown in Figure 1, TIMP-3 protein levels in the BMSC lysate (synthesized TIMP-3) and supernatant (secreted TIMP-3) were elevated for at least 6 days after timp-3 transfection $(P<.01)$, and MMP-2 activity was decreased in medium cultured with BMSC-T3 $(P<.05$ vs BMSC), confirming that the TIMP-3 expressed by the BMSC-T3 cells was functional (Figure 1).

\section{In Vivo Studies}

TIMP-3 overexpression reduced myocardial MMP activity. After MI, cardiac MMP-9 and MMP-2 activities increased. Gelatin zymography provided an estimate of protease activity (after removal of any inhibition by natural TIMPs). By this measure, BMSC-T3 implantation significantly reduced the activities of both MMP-9 $(P<.01$ vs BMSC, $P<.05$ vs medium $)$ and MMP-2 $(P<.01$ vs BMSC and medium) at 3 days after cell transplantation (Figure 2, $A$ and $B$ ), despite the fact that neither MMP-9 nor -2 protein levels (assessed by immunoblotting, relative to internal standard glyceraldehyde-3-phosphate dehydrogenase levels) differed significantly among groups at this time point (data not shown). No significant differences in MMP-9 and -2 expressions or activities were observed among groups beyond 3 days after transplantation. Implantation of vector- transfected BMSCs did not significantly change MMP activities compared to medium implantation at any time point.

TIMP-3 overexpression reduced myocardial TNF- $\alpha$ levels. MI significantly increased myocardial TNF- $\alpha$ levels (from $0.21 \pm 0.01 \mathrm{pg} / \mu \mathrm{g}$ of TNF- $\alpha$ in the normal myocardium), producing a spike during the acute phase (1.67 \pm $0.2 \mathrm{pg} / \mu \mathrm{g}$ ), followed by a reduction on day 7 (to $1.22 \pm$ $0.04 \mathrm{pg} / \mu \mathrm{g}$ ) in the medium recipients. BMSC-T3 implantation decreased TNF- $\alpha$ levels during the acute phase (to 1.01 $\pm 0.06 \mathrm{pg} / \mu \mathrm{g} ; P<.05$ vs BMSC and medium), but BMSC implantation alone did not $(1.49 \pm 0.2 \mathrm{pg} / \mu \mathrm{g})$. The decrease in TNF- $\alpha$ levels persisted at day 7 in the BMSC-T3 group, at which time levels were statistically similar among the groups.

TIMP-3 overexpression enhanced the early reduction of border zone apoptosis by BMSCs. Three days after implantation, TUNEL staining revealed a significant reduction in apoptosis in the border zone of BMSC-implanted hearts relative to medium controls $(P<.05)$. Implantation of BMSC-T3 cells significantly enhanced the early antiapoptotic effect of BMSC implantation $(P<.05$ vs BMSC), which persisted in the BMSC-T3 group at day $7(P<.05$ vs medium, Figure 2, $C$ to $G$ ). No significant differences were observed among groups at day 28 .

TIMP-3 overexpression enhanced the preservation of remote myocardial collagen by BMSCs. MI resulted in significant fragmentation and thinning of the matrix fibrils (Figure 3,A to $D$ ). Compared with medium injection, BMSC and BMSC-T3 transplantation significantly reduced collagen degradation in the remote myocardium at day 28 after cell implantation $(P<.05$ for all groups; Figure 3E). Compared with the medium control group, both length and diameter of the collagen fibrils were preserved by BMSC implantation $(P<.05$ for both measures). These effects were significantly enhanced with BMSC-T3 implantation $(P<$ .05 for both measures vs BMSC and medium control group; Figure $3, F$ and $G$ ).

TIMP-3 overexpression delayed early blood vessel formation in the border zone. Following MI, medium-injected hearts exhibited low capillary densities in the border

FIGURE 2. In vivo analysis of matrix metalloproteinase $(M M P)$ activity and apoptosis. A, B, Densitometry analyses estimating MMP activity in myocardial extracts at days 3, 7, and 28 after implantation of culture medium, bone marrow stromal cells (BMSCs), or timp-3-transfected BMSCs (BMSC-T3). The pooled results demonstrate that MMP-9 (A) and MMP-2 (B) gelatinolytic activities were reduced at day 3 after implantation of BMSC-T3 ( $\mathrm{n}=6$ per group per time point). Gelatin zymography does not measure what activity is inactivated by natural inhibitors in vivo. C-F, Representative light micrographs $(\times 400)$ illustrating terminal deoxynucleotidyl transferase-mediated dUTP nick end labeling staining of apoptotic cells (arrows) in the border zone of mouse hearts 3 days after implantation of medium (C), BMSCs (D), or BMSC-T3 (E). Normal myocardium (No MI, F) is presented as a positive control. Scale bar $=50 \mu \mathrm{m}$ in (CF). G, Apoptotic nuclei (expressed as a $\%$ of total cells per field on days [D] 3, 7, and 28 after implantation; $\mathrm{n}=5$ per group per time point) were significantly reduced at D3 with BMSC implantation, and further reduced with BMSC-T3 implantation. The depression in apoptotic cell numbers persisted at D7 in the BMSC-T3 compared with the medium group. No significant differences were observed between groups at D28. Data are mean \pm standard error of the mean. $* P<.05$ versus medium, $* * P<.01$ versus medium; $\# P<.05$ versus BMSCs; $\ddagger P<.01$ versus BMSCs. 


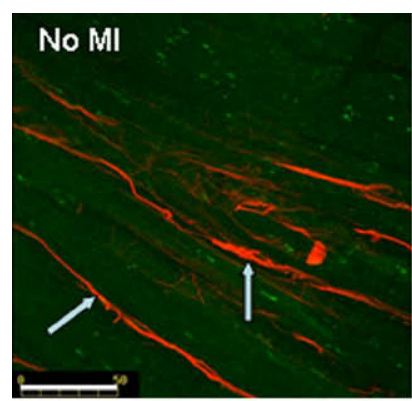

A
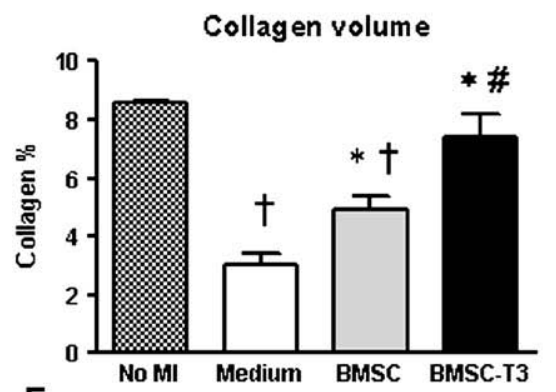

B
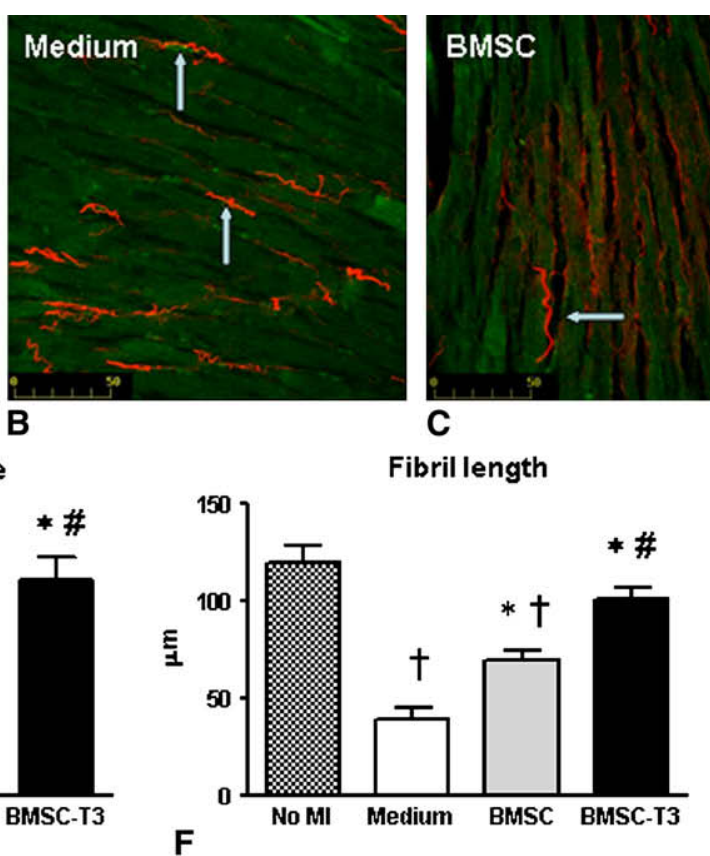

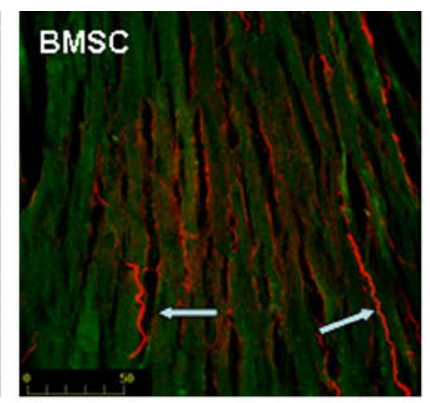

C

\begin{abstract}
C
\end{abstract}

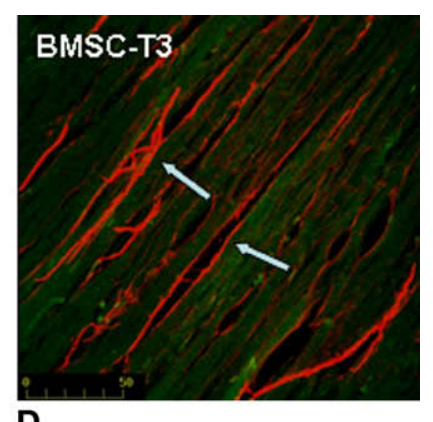

Fibril diameter



FIGURE 3. Collagen content and structure in the remote myocardium. A-D, Representative confocal micrographs (left ventricular sections) showing the fibrillar collagen network (stained with picrosirius red, arrows) in normal myocardium (No MI, A), and in the remote (noninfarcted) myocardium of infarcted animals, 28 days after implantation of medium (B), bone marrow stromal cells (BMSC, C) or timp-3-transfected BMSCs (BMSC-T3, D). Cardiomyocytes appear green due to autofluorescence. Scale bar $=50 \mu \mathrm{m}$ in (A-D). Collagen fibers and connectivity were clearly preserved in the BMSC group and further preserved in the BMSC-T3 group. E-G, Collagen content (expressed as \% of pixel ${ }^{2}$, E), fibril length (F), and fibril diameter (G), determined for all 4 groups ( $\mathrm{n}=6$ per group for Medium, BMSC, BMSC-T3; $\mathrm{n}=4$ for $N o M I$ ) by computer image analysis of confocal stacks, were all increased to $N o$ MI levels by BMSC-T3 implantation. Data are mean \pm standard error of the mean. $* P<0.05$ versus medium, $\# P<.05$ versus BMSC, $\dagger P<.05$ versus No MI.

zone (Figure 4, $A$ to $G$ ). BMSC implantation significantly increased capillary densities in this region early (by day $3, P<$ .05 vs BMSC-T3 and medium). Interestingly, TIMP-3 overexpression temporarily reduced the effect of the implanted cells on capillary formation early after implantation (at day 3) but not later, as capillary densities were similarly elevated $(P<.05)$ relative to medium controls in both BMSC and BMSC-T3 groups at day 7 after implantation (Figure $4, H$ ).

TIMP-3 overexpression enhanced the preservation of systolic function by BMSCs. Echocardiographic measurements of LV end diastolic dimension showed significant LV dilatation in the medium-implanted group as early as 3 days after MI, worsening until the end of the experiments at 28 days (Figure 5, $A$ to $C$ ). BMSC and BMSC-T3 implantation significantly reduced LV dilatation (relative to controls) at 7 and 28 days following MI $(P<.05$ group and time effects by 2-way ANOVA), with beneficial effects evident earlier (by day 3 ) in the BMSC-T3 group (Figure 5, $C$ ).

Systolic function decreased progressively after $\mathrm{MI}$ in the medium control group. BMSC implantation significantly improved systolic function (FAC) compared with the medium control group at days $7(P<.05)$ and $28(P<.05)$ following treatment. TIMP-3 overexpression further increased the functional benefits of cell implantation $(P<.05$ for
BMSC-T3 vs BMSC at days 3 and 28), and the effects were evident earlier, by 3 days following cell treatment (Figure 5, D).

Cell transplantation preserved LV morphometry. Twenty-eight days after cell implantation, morphologic analysis demonstrated a significantly smaller $(P<0.01)$ scar area in the cell-implanted groups than in the medium control group (Figure 5, E). In agreement with the echocardiographic data, cell transplantation also reduced LV dilatation to a level similar to that seen in noninfarcted myocardium (Figure 5, F).

\section{DISCUSSION}

Cell transplantation improves ventricular function after an MI, ${ }^{4,20-23}$ primarily due to paracrine cytokine activation that induces angiogenesis, marrow progenitor cell recruitment, and matrix modulation ${ }^{1}$; however, functional recovery may be enhanced by cell-based gene therapy. Here, BMSCs transplanted immediately after MI preserved matrix structure in the remote (viable) myocardium of timp$3^{-1}$ mice, and overexpressing TIMP-3 in the implanted BMSCs significantly enhanced these effects. The timp $-3^{-1}$ mice exhibit exaggerated ECM degradation and ventricular dilatation following coronary ligation, ${ }^{13-15}$ which may 

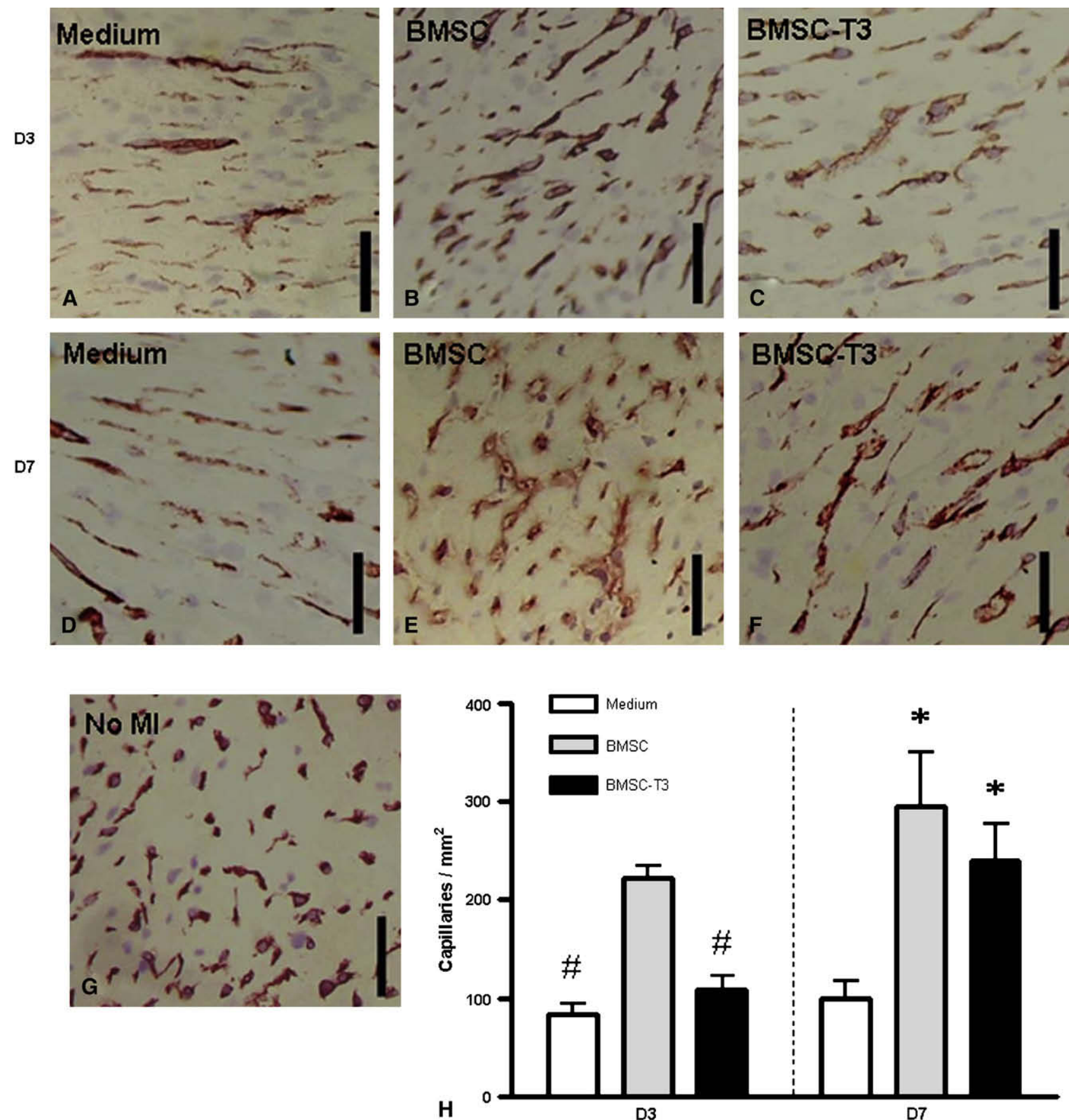

FIGURE 4. Capillary density. A-G, Representative light micrographs $(\times 250)$ showing CD31 staining (vascular structure; brown in color) in the infarct border zone (A-F) of hearts at days (D) 3 and 7 after implantation of medium (A, D), bone marrow stromal cells (BMSC, B, E) or timp-3-transfected BMSCs (BMSC-T3, C, F). Normal myocardium (No MI, G) was a positive control. Scale bar $=25 \mu \mathrm{m}$ in A-G. H, Blood vessel density (expressed as number of capillaries per $\mathrm{mm}^{2} ; \mathrm{n}=5$ per group per time point) was significantly greater at D3 with BMSC implantation compared with BMSC-T3. By D7, vessel density was equally increased in both cell transplant groups. Data are mean \pm standard error of the mean. $* P<.05$ versus medium, $\# P<.05$ versus BMSC.

be similar to that seen in patients who progress rapidly to heart failure after an MI (perhaps due to an inadequate TIMP injury response). ${ }^{6,18}$ This preliminary study establishes the proof of concept that cell-based gene therapy could modify matrix modulation following an MI. Studies in wild-type rodents and large animals will be required to determine whether the approach is clinically applicable. If it is, then this technique might provide an opportunity to 


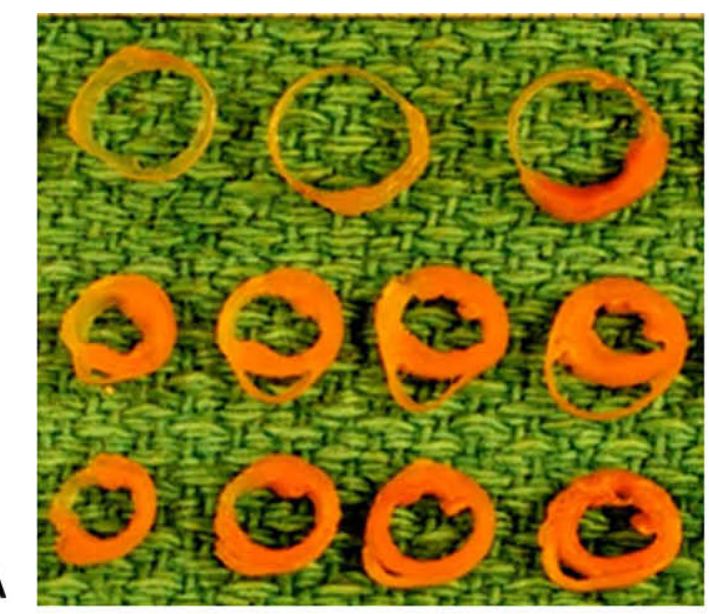

Indexed LV end diastolic dimension

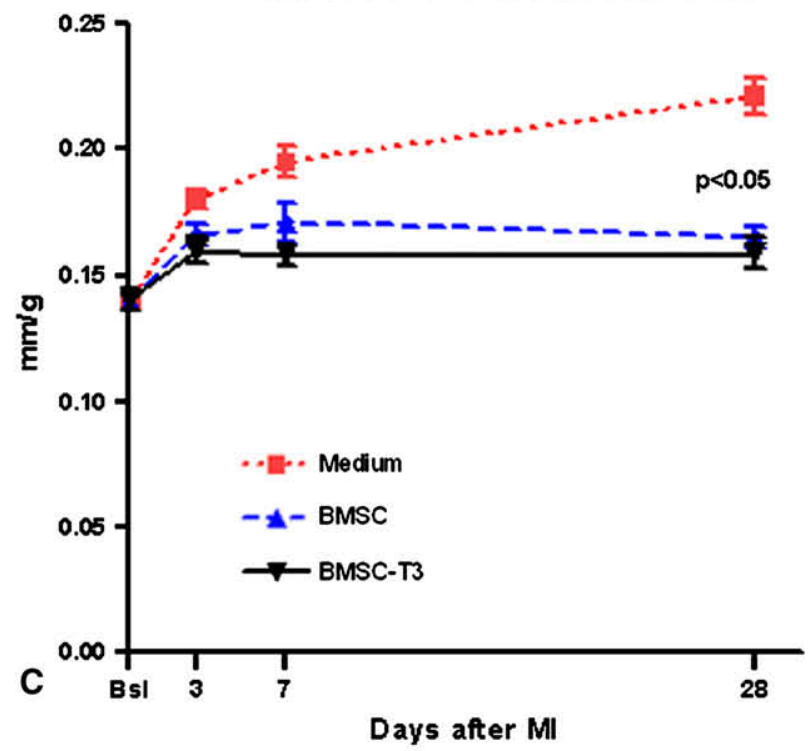

$\%$ LV infarcted area at D28

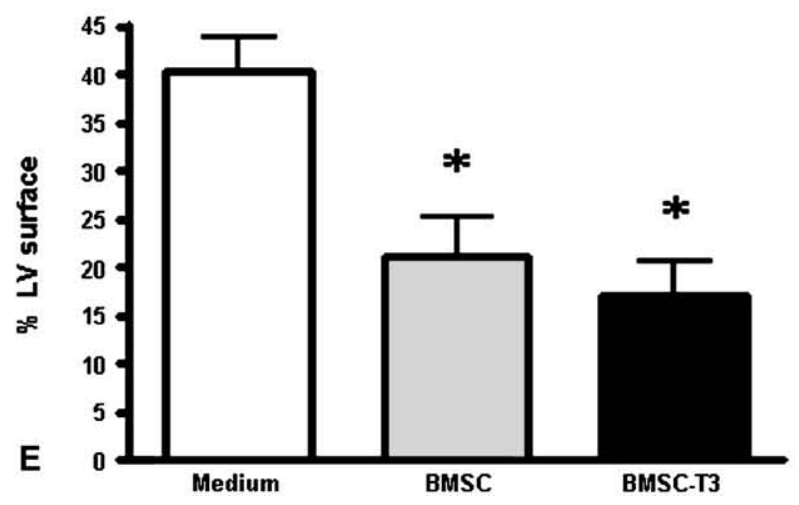

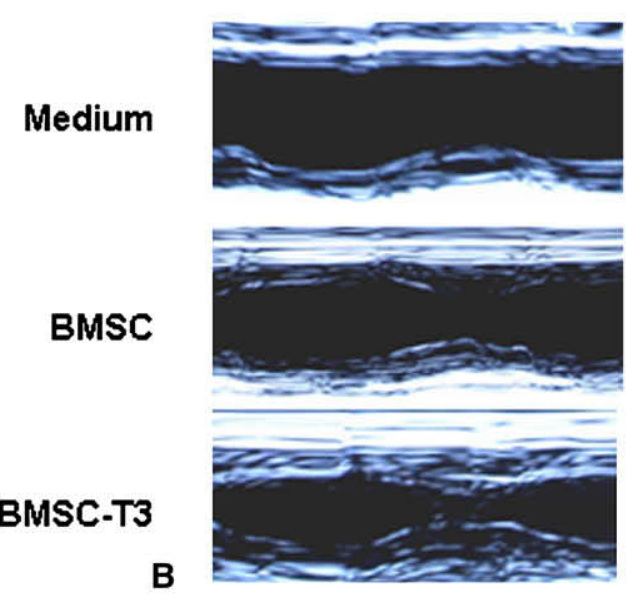

LV Fractional area change

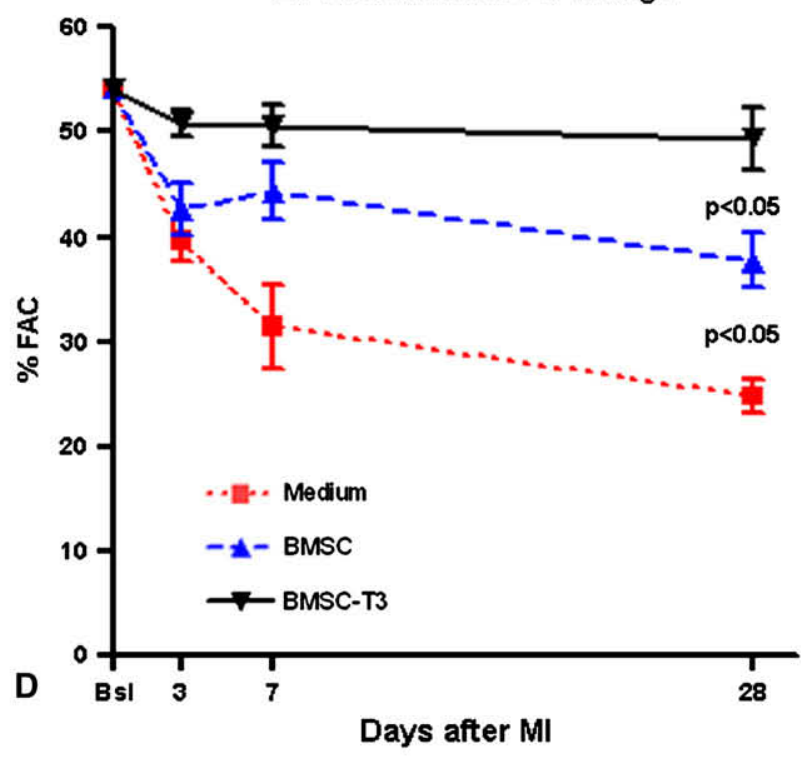

Indexed LV chamber volume at D28

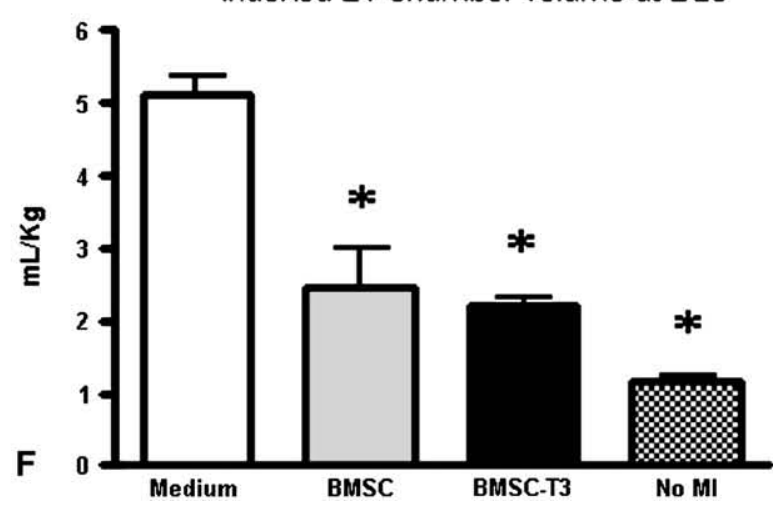


rejuvenate stem cells in elderly patients whose natural regenerative capacity is diminished.

Cell-based gene therapy may boost the paracrine effects of cell transplantation. Ventricular function was enhanced by transfecting implanted cells with the genes for stem cell factor, vascular endothelial growth factor (VEGF), insulinlike growth factor, and/or Akt. ${ }^{20-24}$ This is the first study to show that TIMP-3 overexpression in the implanted cells enhanced the preservation of the matrix structure after an MI. The early reduction in capillary density by BMSC-T3s may have coincided with the early inhibition of MMPs, as matrix degradation is required for endothelial cell mobilization and the branching of new blood vessels. The early effects on capillary density could also be attributed to alternate (but slower) angiogenic pathways. Alternatively, TIMP-3 overexpression may have inhibited VEGF-mediated angiogenesis and induced other secondary effects. ${ }^{25}$

We have previously suggested that cell transplantation after an MI may modify matrix remodeling in the remote myocardium as well as in the infarct area, but this effect has been difficult to demonstrate due to the multiple events associated with coronary ligation. ${ }^{6,13}$ In a hamster model of progressive cardiomyopathy, we showed that cell implantation preserved the collagen network and the regional MMP/TIMP balance in both the implanted area and the remote myocardium. ${ }^{4}$ In rats following an MI, we found that cells implanted into the infarct area reduced matrix remodeling in that area. ${ }^{26}$ The current study demonstrated that BMSCs implanted into the infarct area of timp $-3^{-1}$ mice promoted matrix preservation not only in that area but also in the remote myocardium. This finding provides further support for the theory that matrix homeostasis in the remote myocardium is a critical determinant for the improvement of cardiac function by implanted cells.

In addition to affecting matrix modulation, TIMP-3 overexpression may also have contributed to the reduced cardiac production of TNF- $\alpha$, which induces adverse cardiac remodeling and ventricular dysfunction. ${ }^{27}$ TIMP-3 is a potent, endogenous inhibitor of ADAMs (a disintegrin and a metalloproteinase domain) and TNF- $\alpha$ converting enzyme, ${ }^{28,29}$ which are increased in the hearts of timp- $3^{-}$mice. ${ }^{13}$ In the current study, implanting cells overexpressing TIMP-3 significantly modified the early pattern of post-MI TNF$\alpha$ levels relative to that observed with vector-transfected BMSCs. TNF- $\alpha$ also increases apoptosis and MMP gene expression, ${ }^{27}$ which may explain further reductions in cell loss and matrix structural remodeling in mice implanted with the gene-enhanced cells.

Cell-based gene therapy may permit the regulated, transient MMP inhibition that has not been achieved by current approaches. ${ }^{10}$ Jayasankar and colleagues ${ }^{12}$ overexpressed TIMP-1 by intramyocardial gene transfer in the border zone after coronary ligation in rats. They observed transient inhibition of MMP-1 activity as well as limited improvements in systolic function and geometric remodeling. Gene-enhanced cells influence not only the infarct (implanted) area but also the border zone and the noninfarcted myocardium. ${ }^{21,23}$ We previously reported that the transient release of angiogenic gene products following cell-based gene therapy produced prolonged (6-month) improvements in capillary density and cardiac function. ${ }^{2}$ In the current study, we observed a transient ( 6-day) elevation of TIMP-3 mRNA in the transfected cells. We believe that short-term, regulated amplification of the TIMP response with this clinically relevant approach may confer longterm benefits for matrix modulation in patients. However, we did not determine the number of cells engrafting in the heart, and we did not compare our results to those with gene therapy alone or gene therapy using inert cells.

Paracrine mediators likely act through multiple, diverse, and interrelated mechanisms to produce synergistic effects on the remodeling process. However, although future studies will be required to determine whether TIMP-3-enhanced cell transplantation will modify post-MI matrix remodeling in wild-type mice or humans, the current study suggests that cell-based gene therapy is a potentially effective method to generate transient MMP inhibition and achieve functional recovery following an MI.

R.-K.L. is a Career Investigator of the Heart and Stroke Foundation of Canada and holds a Canada Research Chair in cardiac regeneration. We thank Rama Khokha for providing and genotyping the timp $-3^{{ }^{\prime}}$ mice and Heather McDonald Kinkaid for manuscript preparation and editing.

FIGURE 5. Left ventricular $(L V)$ morphometry and function. A, Representative macrographs of heart slices at 28 days after myocardial infarction $(M I)$ and implantation of medium, bone marrow stromal cells (BMSC), or timp-3-transfected-BMSCs (BMSC-T3). Increased infarct size and LV dilatation is apparent in medium control hearts compared with those from BMSC and BMSC-T3 groups. B, These observations are confirmed by echocardiographic parasternal smallaxis M mode images of the hearts for morphologic study. C, By echocardiography ( $\mathrm{n}=6$ per group per time point), LV dilatation (body weight-indexed LV end diastolic dimension in $\mathrm{mm} / \mathrm{g}$ ) over 28 days following MI was significantly reduced (relative to medium controls) after implantation of BMSC (at days 7 and 28; $P<.05$ ) and BMSC-T3 (at days 3, 7, 28; $P<.01$ ). D, LV systolic function (fractional area change in \%) over 28 days following MI was significantly preserved after implantation of BMSC (compared with medium controls) and BMSC-T3 (compared with BMSC and medium groups). E, F, By morphometric assessment ( $\mathrm{n}=6$ per group), LV infarcted areas (expressed as \% of LV surface, E), and body weight-indexed LV chamber volumes (normal heart [No MI, $\mathrm{n}=3$ ] as control, F) were significantly smaller (compared with medium controls) at 28 days $(D)$ after BMSC or BMSC-T3 implantation. No significant differences were observed between BMSC and BMSC-T3 groups. Data are mean \pm standard error of the mean. $* P<.05$ versus medium. 


\section{References}

1. Fazel S, Cimini M, Chen L, Li S, Angoulvant D, Fedak P, et al. Cardioprotective c-kit+ cells are from the bone marrow and regulate the myocardial balance of angiogenic cytokines. J Clin Invest. 2006;116:1865-77.

2. Kim C, Li RK, Li G, Zhang Y, Weisel RD, Yau TM. Effects of cell-based angiogenic gene therapy at 6 months: persistent angiogenesis and absence of oncogenicity. Ann Thorac Surg. 2007;83:640-6.

3. Yau TM, Kim C, Li G, Zhang Y, Fazel S, Spiegelstein D, et al. Enhanced angiogenesis with multimodal cell-based gene therapy. Ann Thorac Surg. 2007;83:1110-9.

4. Fedak PW, Szmitko PE, Weisel RD, Altamentova SM, Nili N, Ohno N, et al. Cell transplantation preserves matrix homeostasis: a novel paracrine mechanism. J Thorac Cardiovasc Surg. 2005;130:1430-9.

5. Peterson JT, Li H, Dillon L, Bryant JW. Evolution of matrix metalloprotease and tissue inhibitor expression during heart failure progression in the infarcted rat. Cardiovasc Res. 2000;46:307-15.

6. Fedak PW, Altamentova SM, Weisel RD, Nili N, Ohno N, Verma S, et al. Matrix remodeling in experimental and human heart failure: a possible regulatory role for TIMP-3. Am J Physiol Heart Circ Physiol. 2003;284:H626-34.

7. Ducharme A, Frantz S, Aikawa M, Rabkin E, Lindsey M, Rohde LE, et al. Targeted deletion of matrix metalloproteinase- 9 attenuates left ventricular enlargement and collagen accumulation after experimental myocardial infarction. J Clin Invest. 2000;106:55-62.

8. Webb CS, Bonnema DD, Ahmed SH, Leonardi AH, McClure CD, Clark LL, et al. Specific temporal profile of matrix metalloproteinase release occurs in patients after myocardial infarction: relation to left ventricular remodeling. Circulation. 2006;114:1020-7.

9. Mukherjee R, Brinsa TA, Dowdy KB, Scott AA, Baskin JM, Deschamps AM, et al. Myocardial infarct expansion and matrix metalloproteinase inhibition. Circulation. 20034;107:618-25.

10. Spinale FG, Escobar GP, Hendrick JW, Clark LL, Camens SS, Mingoia JP, et al. Chronic matrix metalloproteinase inhibition following myocardial infarction in mice: differential effects on short and long-term survival. J Pharmacol Exp Ther. 2006;318:966-73.

11. Hudson MP, Armstrong PW, Ruzyllo W, Brum J, Cusmano L, Krzeski P, et al. Effects of selective matrix metalloproteinase inhibitor (PG-116800) to prevent ventricular remodeling after myocardial infarction: results of the PREMIER (Prevention of Myocardial Infarction Early Remodeling) trial. J Am Coll Cardiol. 2006;48:15-20.

12. Jayasankar V, Woo YJ, Bish LT, Pirolli TJ, Berry MF, Burdick J, et al. Inhibition of matrix metalloproteinase activity by TIMP-1 gene transfer effectively treats ischemic cardiomyopathy. Circulation. 2004;110:II180-6.

13. Fedak PW, Smookler DS, Kassiri Z, Ohno N, Leco KJ, Verma S, et al. TIMP-3 deficiency leads to dilated cardiomyopathy. Circulation. 2004;110:2401-9.

14. Leco KJ, Waterhouse P, Sanchez OH, Gowing KL, Poole AR, Wakeham A, et al. Spontaneous air space enlargement in the lungs of mice lacking tissue inhibitor of metalloproteinases-3 (TIMP-3). J Clin Invest. 2001;108:817-29.
15. Tian H, Cimini M, Fedak PWM, Altamentova S, Fazel S, Huang ML, et al. TIMP3 deficiency accelerates cardiac remodeling after myocardial infarction. $J \mathrm{Mol} \mathrm{Cell}$ Cardiol. 2007;43:733-43.

16. Kiani C, Lee V, Cao L, Chen L, Wu Y, Zhang Y, et al. Roles of aggrecan domains in biosynthesis, modification by glycosaminoglycans and product secretion. Biochem J. 2001;354(Pt 1):199-207.

17. Degousee N, Ghomashchi F, Stefanski E, Singer A, Smart BP, Borregaard N, et al. Groups IV, V, and X phospholipases A2s in human neutrophils: role in eicosanoid production and gram-negative bacterial phospholipid hydrolysis. J Biol Chem. 2002;277:5061-73.

18. Fedak PW, Moravec CS, McCarthy PM, Altamentova SM, Wong AP, Skrtic M, et al. Altered expression of disintegrin metalloproteinases and their inhibitor in human dilated cardiomyopathy. Circulation. 2006;113:238-45.

19. Wijsman JH, Jonker RR, Keijzer R, van d V, Cornelisse CJ, van Dierendonck JH. A new method to detect apoptosis in paraffin sections: in situ end-labeling of fragmented DNA. J Histochem Cytochem. 1993;41:7-12.

20. Fazel S, Chen L, Weisel RD, Angoulvant D, Seneviratne C, Fazel A, et al. Cell transplantation preserves cardiac function after infarction by infarct stabilization: augmentation by stem cell factor. J Thorac Cardiovasc Surg. 2005; $130: 1310$

21. Liu TB, Fedak PW, Weisel RD, Yasuda T, Kiani G, Mickle DA, et al. Enhanced IGF-1 expression improves smooth muscle cell engraftment after cell transplantation. Am J Physiol Heart Circ Physiol. 2004;287:H2840-9.

22. Mangi AA, Noiseux N, Kong D, He H, Rezvani M, Ingwall JS, et al. Mesenchymal stem cells modified with Akt prevent remodeling and restore performance of infarcted hearts. Nat Med. 2003;9:1195-201.

23. Yau TM, Kim C, Li G, Zhang Y, Weisel RD, Li RK. Maximizing ventricular function with multimodal cell-based gene therapy. Circulation. 2005;112:I123-8.

24. Yasuda T, Weisel RD, Kiani C, Mickle DA, Maganti M, Li RK. Quantitative analysis of survival of transplanted smooth muscle cells with real-time polymerase chain reaction. J Thorac Cardiovasc Surg. 2005;129:904-11.

25. Gnecchi M, He H, Noiseux N, Liang OD, Zhang L, Morello F, et al. Evidence supporting paracrine hypothesis for Akt-modified mesenchymal stem cell-mediated cardiac protection and functional improvement. FASEB J. 2006;20:661-9.

26. Mizuno T, Yau TM, Weisel RD, Kiani CG, Li RK. Elastin stabilizes an infarct and preserves ventricular function. Circulation. 2005;112:I81-8.

27. Sun M, Dawood F, Wen WH, Chen M, Dixon I, Kirshenbaum LA, et al. Excessive tumor necrosis factor activation after infarction contributes to susceptibility of myocardial rupture and left ventricular dysfunction. Circulation. 2004;110: 3221-8.

28. Amour A, Slocombe PM, Webster A, Butler M, Knight CG, Smith BJ, et al. TNFalpha converting enzyme (TACE) is inhibited by TIMP-3. FEBS Lett. 1998;435: $39-44$.

29. Woessner JF Jr. That impish TIMP: the tissue inhibitor of metalloproteinases-3. J Clin Invest. 2001;108:799-800. 


\section{APPENDIX E1}

\section{Supplementary Methods}

The bone marrow stromal cells (BMSCs) employed in these studies have been previously employed to improve ventricular function after a myocardial infarction and to act as a carrier for cell-based gene therapy. These cells are particularly appropriate for this purpose because of their ability not only to induce angiogenesis but also to transdifferentiate into a variety of cell types required for infarct healing: endothelial, smooth muscle cells, and myofibroblasts. However, BMSCs are not easily identified by surface markers and therefore are not easily separated by common cell-sorting techniques. Instead, BMSCs are identified by their ability to adhere to plastic surfaces and to rapidly expand in response to cytokines.

\section{In Vitro Studies}

BMSCs: Isolation, expansion, and characterization. BMSCs were isolated from C57BL/6 mice and cultured as previously described. ${ }^{\mathrm{E} 1}$ Whole bone marrow was plated in Iscove's modified Dulbecco's medium (Gibco, Rockville, Md) supplemented with $10 \%$ fetal bovine serum (Gibco), penicillin $(100 \mathrm{U} / \mathrm{mL})$, and streptomycin $(100 \mathrm{U} / \mathrm{mL})$. Cells were cultured at $37^{\circ} \mathrm{C}$ with $5 \% \mathrm{CO}_{2}$ in humid atmosphere. Nonadherent cells were removed by aspiration 48 hours later. Adherent cells were harvested in $0.05 \%$ Trypsin solution with $1 \mathrm{mmol}$ ethylenediaminetetraacetic acid and subcultured. Cultured cell phenotype was assessed by fluorescence-activated cell sorting (FACS), using fluorescein isothiocyanate-conjugated or phycoerythrin-conjugated monoclonal antibodies recognizing Sca-1, CD81, CD34, CD45, CD31, and c-kit (Becton Dickinson, Franklin Lakes, NJ). Analysis was with an EPICS XL-MCL flow cytometer (Coulter, Beckman, Fullerton, Calif) equipped with Expo32 ACD Xa software.

Generation of BMSCs overexpressing murine tissue inhibitor of matrix metalloproteinase-3. cDNA for murine tissue inhibitor of matrix metalloproteinase-3 (TIMP-3) was cloned into pcDNA3.1+(Invitrogen, Carlsbad, Calif) as previously described. ${ }^{\mathrm{E} 2}$ The purified plasmid was transfected into BMSCs (BMSC-T3) by liposomal transfection using lipofectamine 2000 (Invitrogen) as per manufacturer's instructions. Cotransfection with pSV- $\beta$-galactosidase control vector (Promega, Madison, Wis) was performed to assess transfection efficiency. $\beta$-galactosidase expression was assessed after staining of BMSCs as per manufacturer's instructions (Promega). Blue-stained $\beta$-galactosidase positive cells were counted on 10 random fields and expressed as percent of total cells per field. BMSCs transfected with unmodified pcDNA3.1+ were stained as negative controls.

Cellular TIMP-3 expression. Cellular TIMP-3 mRNA levels at $0,1,2,3$, and 6 days after transfection $(n=5$ per group per time point) were assessed by semiquantitative reverse-transcriptase polymerase chain reaction, using specific primers, as previously described. ${ }^{\mathrm{E} 3}$

Protein levels of synthesized (BMSC lysate) and secreted (supernatant) TIMP-3 were evaluated with an immunoblotting procedure using a polyclonal rabbit anti-human antibody for TIMP-3 (1:500, Triple Point Biologics, Forest Groves, Orel) at $0,3,6$, and 10 days after gene transfection ( $\mathrm{n}=6$ per group per time point).

Cellular matrix metalloproteinase-2 expression and activity. Protein levels of matrix metalloproteinase-2 (MMP-2) in the cultured cells and culture medium 3 days ( $\mathrm{n}=6$ per group) after timp -3 transfection were quantified by Western blot, using a rabbit anti-human antibody against MMP-2 (1:1000, Chemicon International, Billerica, Mass.), as previously described. ${ }^{\mathrm{E} 4}$

Activities of MMP-2 were evaluated at 3 days after gene transfection using gelatin zymography, as previously described. ${ }^{\mathrm{E}}$ Equal amounts $(10 \mu \mathrm{g})$ of protein $(\mathrm{n}=6$ per group $)$ were fractionated by $10 \%$ zymography gels impregnated with $0.1 \%$ gelatin (Novex, Invitrogen). Gels were renatured with $2 \times 2.5 \%$ Triton X-100 washes for 30 minutes at room temperature. The gels were then equilibrated with developing buffer $\left(49.1 \mathrm{mmol} / \mathrm{L}\right.$ Tris, $4.81 \mathrm{mmol} / \mathrm{L} \mathrm{CaCl}_{2}$, $0.002 \% \mathrm{NaN}_{3}$ ) at room temperature for 15 minutes with agitation. Finally, gels were incubated with developing buffer 18 to 20 hours at $37^{\circ} \mathrm{C}$. Coomassie blue R-250 (Sigma Chemical Co, St Louis, Mo) staining was used to detect enzymatic activity; following staining, areas of gelatinolytic activity appeared as clear bands against the dark blue background. Bands obtained from immunoblot and gelatin zymography were quantified using densitometric analysis. The latent (pro) and active forms of MMP-2 (72 and 68 $\mathrm{kDa}$, respectively) were detected. Molecular weights of the bands were estimated using recombinant MMP-2 protein. Integrated density values (band area $\mathrm{X}$ relative intensity) of active MMP-2 were used as markers of MMP-2 activation.

\section{In Vivo Studies}

Functional assessment. Left ventricular (LV) dilatation and systolic function were evaluated by echocardiography (Sequoia C256 System, Siemens Medical; 15-MHz linear array transducer) prior to and 3, 7, and 28 days after MI and cell or medium implantation ( $\mathrm{n}=6$ per group). M-mode and 2-dimensional images were obtained in the parasternal short axis at the level of the papillary muscles. For each measurement, 3 consecutive cardiac cycles were recorded and averaged by a single blinded examiner. LV end diastolic dimension was determined in M-mode imaging and indexed to the animal's body weight recorded at the time of echocardiography. In 2-dimensional imaging, the LV end diastolic area (LVEdA) was determined as the largest cavity 
size and the LV end systolic area (LVEsA) as the smallest. Fractional area change (FAC) was calculated as follows: FAC $=(($ LVEdA - LVEsA $) /$ LVEdA $) \times 100$. Afterward, hearts from each group were fixed for morphometric and collagen analyses.

Morphometric assessment. At 28 days after implantation $(\mathrm{n}=6$ each for medium, BMSC, BMSCs transfected 3 days earlier with TIMP-3 plasmid [BMSC-T3] groups; $n=3$ for normal myocardium), following perfusion fixation with buffered $10 \%$ formalin at controlled ventricular pressure, left ventricles were cut into 1-mm-thick transverse slices from apex to base. Heart slices were photographed with a digital camera, and unmagnified images were analyzed by a blinded observer using Image $\mathrm{J}$ software. The border between infarcted and noninfarcted myocardium was clearly identifiable in each image (the infarcted myocardium appeared visibly thinner and paler in color than the noninfarcted myocardium). Infarct size was measured as described by Takagawa and colleagues, ${ }^{\mathrm{E} 5}$ with modifications. Briefly, epicardial infarct length and epicardial circumference of LV myocardium were manually traced and automatically measured in serial digital images. To calculate infarct and LV areas for each slice, infarct length or LV circumference were multiplied by the 1-mm thickness. To calculate infarct size (expressed as a percentage), the sum of infarct areas from all slices was divided by the sum of LV areas from all slices (including those without infarct scar) and multiplied by 100 . LV chamber volume was measured in the same manner and indexed by body weight $(\mathrm{mL} / \mathrm{kg})$.

\section{SUPPLEMENTARY RESULTS}

\section{In Vitro Studies}

Characterization of cultured BMSCs. The phenotypes of cultured BMSCs at passages 10, 20, and 40 were evaluated by FACS analysis. The cell population was homogenous, and more than $99 \%$ of cells stably expressed Sca- $1^{+}$, $\mathrm{CD} 81^{+}, \mathrm{CD} 34^{-}, \mathrm{CD} 45^{-}, \mathrm{CD} 31^{-}$, $\mathrm{c}^{-k i t}{ }^{-}$, without contamination by hematopoietic stem cells or endothelial progenitor cells. BMSCs from passage 20 were used in this study to improve cardiac function and as carriers of the timp-3 gene.

Cellular TIMP-3 expression. Gene transfection efficiency, evaluated by staining for $\beta$-galactosidase expression (Figure $1, A$ ), was $15 \% \pm 2 \%$ at 3 days after transfection. TIMP-3 mRNA levels in the gene-transfected cells were significantly greater $(P<.01)$ than those in the vector-transfected cells for the 6-day duration of the study (Figure 1, $B$ and $C$ ). TIMP-3 protein levels in the BMSC lysate (synthesized TIMP-3) and supernatant (secreted TIMP-3) were greatly elevated from baseline for at least 6 days after timp-3 transfection $(P<.01$ for all groups, Figure $1, D$ and $E$ ).

Cellular MMP-2 expression and activity. Gelatin zymography showed a significant reduction in MMP-2 activity in the medium cultured with BMSC-T3 compared with that cultured with BMSC at 3 days after transfection $(P<.01$; Figure $1, F)$, though immunoblot analysis showed no difference in MMP-2 expression between the 2 groups (Figure 1, $G)$. These data confirm that BMSC-T3 cells expressed functional TIMP-3 following gene transfection.

\section{Supplementary References}

E1. Baddoo M, Hill K, Wilkinson R, Gaupp D, Hughes C, Kopen GC, et al. Characterization of mesenchymal stem cells isolated from murine bone marrow by negative selection. J Cell Biochem. 2003;89:1235-49.

E2. Kiani C, Lee V, Cao L, Chen L, Wu Y, Zhang Y, et al. Roles of aggrecan domains in biosynthesis, modification by glycosaminoglycans and product secretion. Biochem J. 2001;354(Pt 1):199-207.

E3. Degousee N, Ghomashchi F, Stefanski E, Singer A, Smart BP, Borregaard N, et al. Groups IV, V, and X phospholipases A2s in human neutrophils: role in eicosanoid production and gram-negative bacterial phospholipid hydrolysis. J Biol Chem. 2002;277:5061-73.

E4. Leco KJ, Waterhouse P, Sanchez OH, Gowing KL, Poole AR, Wakeham A, et al. Spontaneous air space enlargement in the lungs of mice lacking tissue inhibitor of metalloproteinases-3 (TIMP-3). J Clin Invest. 2001;108:817-29.

E5. Takagawa J, Zhang Y, Wong ML, Sievers RE, Kapasi NK, Wang Y, et al. Myocardial infarct size measurement in the mouse chronic infarction model: comparison of area- and length-based approaches. J Appl Physiol. 2007;102:2104-11. 